\title{
Klebsiella pneumoniae With Multiple Antimicrobial Resistance
}

Caio Mendes ${ }^{1,2}$, Carlos Kiffer ${ }^{1,2}$, Adília Segura ${ }^{3}$, Julival Ribeiro ${ }^{3}$ and Philip Turner ${ }^{4}$
Fleury Medical Diagnostic Center, Advisory Group on Antimicrobials and Clinical Microbiology ${ }^{l}$; University of São Paulo², São Paulo, SP; Hospital de Base of Brasília ${ }^{3}$ Brasília, DF, Brazil; Antrazeneca Macclesfield ${ }^{4}$, Cheshire, England

\begin{abstract}
A Klebsiella pneumoniae strain was isolated from the urine of a patient at one of the centers participating in the 2001 edition of the MYSTIC program in Brazil. The initial phenotypic findings of the isolated $K$. pneumoniae presented an unusual MIC of $8 \mu \mathrm{g} / \mathrm{mL}$ to meropenem, $2 \mu \mathrm{g} / \mathrm{mL}$ to imipenem, elevated MICs to broad spectrum cephalosporins (ceftazidime/cefotaxime/cefepime MIC $>256 \mu \mathrm{g} / \mathrm{mL}$ ), aminoglycosides (gentamycin $>256 \mu \mathrm{g} / \mathrm{mL}$ and tobramycin $=48 \mu \mathrm{g} / \mathrm{mL}$ ), piperacillin/tazobactam (MIC $>256 \mu \mathrm{g} / \mathrm{mL}$ ) and susceptibility to ciprofloxacin (MIC $=0.25 \mu \mathrm{g}$ / $\mathrm{mL}$ ). The strain also tested positive for ESBL production with double-disk and E-test methodologies. More detailed investigation revealed that the strain produced a SHV-4 type enzyme and also lacked a $36 \mathrm{kDa}$ outer membrane porin.

Key Words: Klebsiella pneumoniae, drug effects, drug resistance, carbapenems.
\end{abstract}

The Meropenem Yearly Susceptibility Test Information Collection (MYSTIC) is a global, multicentre surveillance program, which compares the activity of meropenem in centres that are prescribers, with that of other broad spectrum antimicrobial agents. The MYSTIC Program is currently active in Brazil and during its second edition all samples have been collected from patients in intensive care units (ICUs) and were involved in the infectious process. The objective of this program is to evaluate the susceptibility pattern of Gram-negative bacilli isolated from Brazilian ICUs. A $K$. pneumoniae strain was isolated from the urine of a patient at one of the centers participating in the 2001 edition of the MYSTIC program in Brazil. This strain presented an unusual resistance pattern with elevated MICs to carbapenems and other broad spectrum antibiotics, and it was further studied.

Received on 22 July 2003; revised 12 January 2004.

Address for correspondence: Dr. Carlos Kiffer. Av. General Waldomiro Lima, 508, Jabaquara, São Paulo/SP, Brazil. Zip code: 04344-070. Phone: (55 11) 5014-7657. Fax: (55 11) 50147601.E-mail: carlos.kiffer@fleury.com.br

The Brazilian Journal of Infectious Diseases 2004;8(1):109-111 (C) 2004 by The Brazilian Journal of Infectious Diseases and Contexto Publishing. All rights reserved.

\section{Case Report}

A $K$. pneumoniae strain was isolated from the urine of a patient at one of the centers participating in the 2001 edition of the MYSTIC program in Brazil. The patient had suffered traumatic head injury and was submitted to mechanical ventilatory support. The patient was hospitalized for 34 consecutive days and also developed pneumonia due to Acinetobacter spp. and methicllinresistant $S$. aureus during the ICU stay, finally leading to death. The patient received multiple intravenous antibacterial agents until etiological identifications and thereafter, as follows: oxacillin $2 \mathrm{~g} \mathrm{q} 4 \mathrm{~h}$ for 2 days; cefazolin $2 \mathrm{~g}$ q6h for 2 days; cloramphenicol $1 \mathrm{~g}$ q6h for 2 days; ceftriaxone $2 \mathrm{~g} \mathrm{q} 12 \mathrm{~h}$ for 7 days; cefepime $2 \mathrm{~g} \mathrm{q} 12 \mathrm{~h}$ for 14 days; and finally, meropenem $1 \mathrm{~g}$ q $8 \mathrm{~h}$ for 7 days, plus vacomycin $1 \mathrm{~g} \mathrm{q} 12 \mathrm{~h}$ for 12 days.

The MICs were determined by E-test methodologies, according to NCCLS guidelines [1]. The ESBL detection assay was also based on the NCCLS standard method and was peformed with the double-disk (approximation disk method with and ceftazidime/ceftazidime-clavulante) and E-test methodologies [1]. The initial phenotypic findings of the isolated $K$. pneumoniae indicated an unusual MIC of $8 \mu \mathrm{g} / \mathrm{mL}$ to meropenem, $2 \mu \mathrm{g} / \mathrm{mL}$ to 
Figure 1. Outer membrane protein profiles determination by gel electrophoresis (with carbapenem resistant and sensitive controls, as well as mutants known to be lacking the $36 \mathrm{KDa} \mathrm{K}$ porin protein)

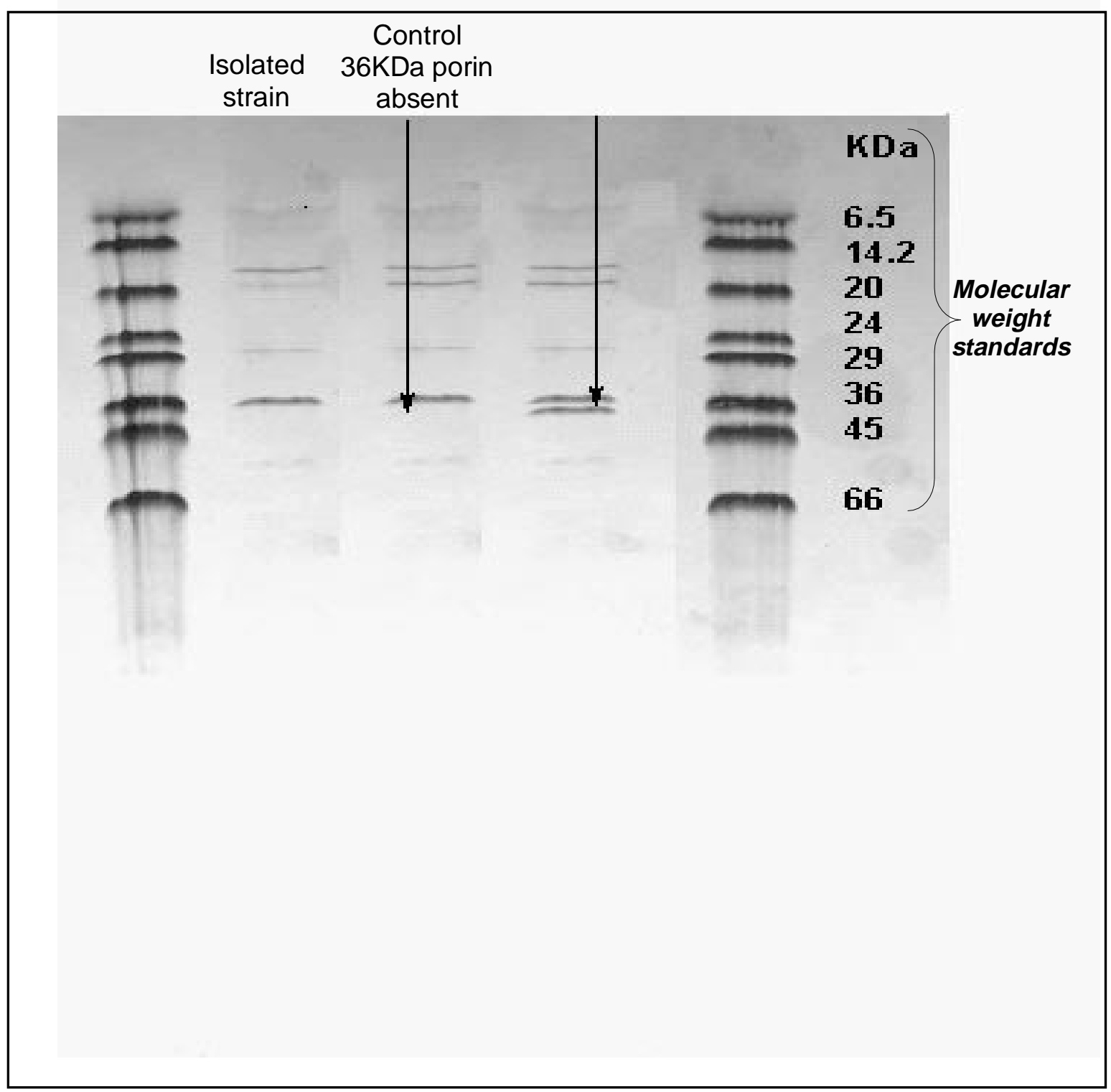

imipenem, elevated MICs to broad spectrum cephalosporins (ceftazidime/cefotaxime/cefepime MIC $>256 \mu \mathrm{g} / \mathrm{mL}$ ), aminoglycosides (gentamycin > $256 \mu \mathrm{g} /$ $\mathrm{mL}$ and tobramycin $=48 \mu \mathrm{g} / \mathrm{mL})$, piperacillin/ tazobactam (MIC $>256 \mu \mathrm{g} / \mathrm{mL}$ ) and susceptibility to ciprofloxacin $(\mathrm{MIC}=0.25 \mu \mathrm{g} / \mathrm{mL})$. The strain also tested positive for ESBL production. Full details of the susceptibility testing methods have been previously described [2]. A detailed investigation was performed, revealing that the strain produced a SHV-4 type enzyme and also lacked a $36 \mathrm{KDa} \mathrm{K}$ outer membrane porin (Figure 1) presumably responsible for this decreased susceptibility.

\section{Discussion}

This K. pneumoniae strain, with an unusual MIC pattern for carbapenems $(8 \mu \mathrm{g} / \mathrm{mL}$ for meropenem and $2 \mu \mathrm{g} / \mathrm{mL}$ for imipenem) was isolated from a center that 
was found to have a meropenem usage density at this particular ICU of 22.5 DDDs/100 beds-day. However, this was apparently a single event and did not characterize a clonal spread associated with high density antimicrobial usage of any agent, since there were no other similar isolates during this period at the institution. This seems to support antimicrobial selective pressure during treatment for this specific patient.

Studies have reported porin-selection in $K$. pneumoniae both in vitro and in vivo due to antimicrobial use [3-5]. Some ESBL(+) porin-deficient K. pneumoniae strains show decreased susceptibility to meropenem, and to a lesser extent to imipenem [6]. Porin loss should be understood as the absence of both OmpK36 and of OmpK35. This isolate presented loss of OmpK36, although most ESBL(+) K. pneumoniae lack OmpK35 (the actual reason for this phenomenon is not presently known). However some of them also lack OmpK36. This strain is characteristic of the latter situation. Nevertheless, it is not possible to affirm in this particular case that the loss of OmpK36 and of OmpK35 is exclusively responsible for this strain's decreased susceptibility. Although this seems highly probable with this particular isolate, it should be noted that additional information is required for understanding its resistance mechanisms. In particular, the presence of other beta-lactamases has to be discarded. It is known that low level resistance to carbapenems can also be explained by the presence of a metallo-betalactamase $[7,8]$ or by the presence (only in a porin-deficient strain) of a plasmid-mediated AmpC-type enzyme $[9,10]$.

Also it was not possible to correlate the porinselection with any specific antibiotic used, particularly because of the multiple agents used consecutively. Bactericidal agents in high doses are less potent inducers of resistance, especially by porin-mutant selection $[11,12]$. Additionally, meropenem apparently has a weaker resistance inducing potential in other species, either per porin-selection or per efflux pumps induction [5]. However, multiple and consecutive antimicrobials were applied and their sequential and additive use might have contributed to the resistance pattern that developed. Therefore, in this particular case, avoiding unnecessary antibiotics and optimizing their use could have been beneficial to minimize resistance pressure.

\section{References}

1. NCCLS 2002. Performance Standards for Antimicrobial Susceptibility Testing: Twelfth informational supplement. NCCLS document M100-S12. NCCLS, Wayne, Pa, USA, 2002.

2. Turner P.J. MYSTIC (Meropenem Yearly Susceptibility est Information Collection): a global overview. J Antimicrob Chemother 2000;46(Topic T2):9-23.

3. Pragai Z., Nagy E. In vitro selection of porin-deficient mutants of two strains of Klebsiella pneumoniae with reduced susceptibilities to meropenem, but not to imipenem. J Antimicrob Chemother 1998;42(6):821-4.

4. Pangon B., Bizet C., Bure A., et al. In vivo selection of a cephamycin-resistant, porin-deficient mutant of Klebsiella pneumoniae producing a TEM-3 betalactamase. J Infect Dis 1989;159(5):1005-6.

5. Martinez-Martinez L., Hernandez-Alles S., Alberti S., et al. In vivo selection of porin-deficient mutants of Klebsiella pneumoniae with increased resistance to cefoxitin and expanded-spectrum-cephalosporins. Antimicrob Agents Chemother 1996;40(2):342-8.

6. Ardanuy C., Liñares J., Domínguez M.A, Hernández-Allés S, Benedí VJ, Martínez-Martínez L. Outer Membrane Profiles of Clonally Related Klebsiella pneumoniae Isolates from Clinical Samples and Activities of Cephalosporins and Carbapenems. Antimicrob Agents Chemother 1998;42(7): 1636-40.

7. Koh T.H., Sng L.H., Babini G.S., et al. CarbapenemResistant Klebsiella pneumoniae in Singapore Producing IMP-1 $\beta$-Lactamase and Lacking an Outer Membrane Protein. Antimicrob Agents Chemother 2001;45(6):1939-40.

8. Yan J.J., Ko W.C., Tsai S.H., et al. Outbreak of Infection with multidrug-resistant Klebsiella pneumoniae carrying blaIMP-8 in a university medical center in Taiwan. J Clin Microbiol 2001;39(12):4433-9.

9. Bradford P.A., Urban C., Mariano N., et al. Imipenem resistance in Klebsiella pneumoniae is associated with the combination of act-1, a plasmid-mediated AmpC $\beta$ lactamase, and the loss of an outer membrane protein. Antimicrob Agents Chemother 1997;41(3)563-9.

10. Martínez-Martínez L., Pascual A., Hernández-Allés S., et al. Roles of $\beta$-lactamases and porins in activities of carbapenems and cephalosporins against Klebsiella pneumoniae. Antimicrob Agents Chemother 1999;43(7):1669-73.

11. Livermore D. Of Pseudomonas, porins, pumps and carbapenems. J Antimicrob Chemother 2001;47:247-250.

12. Stratton C.W. Dead bugs don't mutate: susceptibility issues in the emergence of bacterial resistance. Emerg Infect Dis 2003;9(1):10-6. 